\title{
Research Paper: Comparison of the Effect of Filial and Adlerian Play Therapy on Attention and Hyperactivity of Children With Attention Deficit Hyperactivity Disorder: A Randomized Clinical Trial
}

Hooshang Mirzaie ${ }^{1}$ (D), Afsoon Hassani Mehraban² ${ }^{2}$, Seyed Ali Hosseini' ${ }^{1}$ (D) Fatemeh Ghasemi Fard ${ }^{*}$ (D), Mehdi Jafari Oori ${ }^{3}$ (D)

1. Department of Occupational Therapy, University of Social Welfare and Rehabilitation Sciences, Tehran, Iran.

2. Department of Occupational Therapy, School of Rehabilitation Sciences, Iran University of Medical Sciences, Tehran, Iran

3. Department of Nursing, University of Social Welfare and Rehabilitation Sciences, Tehran, Iran.

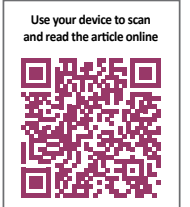

citation: Mirzaie H, Hassani Mehraban A, Hosseini SA, Ghasemi Fard F, Jafari Oori M. Comparison of the Effect of Filial and Adlerian Play Therapy on Attention and Hyperactivity of Children With Attention Deficit Hyperactivity Disorder: A Randomized Clinical Trial. Iranian Rehabilitation Journal. 2019; 17(4):341-350. http://dx.doi.org/10.32598/irj.17.4.341

doi http://dx.doi.org/10.32598/irj.17.4.341

\section{(c) (1) (8)}

Article info:

Received: 15 May 2019

Accepted: 08 Aug 2019

Available Online: 01 Dec 2019

Keywords:

Play therapy, Attention Deficit Hyperactivity Disorder

(ADHD), Children

\begin{abstract}
Objectives: For children with Attention Deficit Hyperactivity Disorder (ADHD), different types of play therapy may have different effects. The aim of this study was to compare the effect of two types of play therapy intervention methods, including a child-parents therapy named Filial Therapy (FT) and a child-therapist therapy known as Adlerian Therapy (AT) on the attention and hyperactivity of these children.
\end{abstract}

Methods: In this randomized clinical trial, which lasted from February 20 to May 5, 2014, 51 boys and girls aged 6-12 years with ADHD were randomly selected and allocated to 3 groups by blocked method (17 subjects in each group). Two of the groups received FT and AT intervention and one group remained as a control group. Participation's parents in the FT group received one session of training play therapy per week for 10 weeks and played with their children at home every day during this time. The AT group received 3 sessions of play therapy for 10 weeks in the clinics. The data of attention and hyperactivity of the subjects were collected in the pre-test, post-test, and a 3-month follow-up by Child Symptom Inventory-4 (CSI-4) and Test of Everyday Attention for Children (TEA-Ch). The Mean, Standard Deviation (SD), and frequency were used as descriptive statistics and the Chi-squared, one-way ANOVA, Man-Whitney, and Kruskal-Wallis tests, as well as Generalized Estimating Equation, were used as analytical statistics in the SPSS V. 22. The P-value of 0.05 was considered significant.

Results: Half of the subjects were male and the Mean \pm SD age of the subjects was $8 \pm 2$ years old. The Mean \pm SD of hyperactivity was $23.94 \pm 13.44,20.82 \pm 11.64$, and $20.76 \pm 11.13$ in the FT group, $17.70 \pm 3.70,15.20 \pm 3.33$, and $15 \pm 3.50$ in the AT group, and $24.25 \pm 10.32,25.38 \pm 11.48$, and $24.81 \pm 11.96$ in the control group. The Mean \pm SD of attention was $8.47 \pm 5.33,15.60 \pm 2.79$, and $15.80 \pm 2.50$ in the FT group, $6.71 \pm 5.31,12.24 \pm 3.33$, and $12.90 \pm 3.12$ in the AT group, and $9.71 \pm 5.36,10.41 \pm 3.24$, and $9.92 \pm 4.89$ in control group. As the result showed, the hyperactivity of the subjects had significantly decreased in the intervention groups $(\mathrm{P}<0.05)$ compared with the control group. Also, the attention of the subjects had significantly increased in the intervention groups $(\mathrm{P}<0.05)$ compared with the control group.

Discussion: Although both methods reduced the severity of hyperactivity and increased the attentional performance of the subjects, the effectiveness of the FT method was more enormous. The finding indicated that the participation of parents in the treatment process could increase the rehabilitation procedure of children with ADHD.

* Corresponding Author:

Address: Department of Occupational Therapy, University of Social Welfare and Rehabilitation Sciences, Tehran, Iran.

Tel: +98 (912) 8013965

E-mail: ghasemifard.ot@yahoo.com 


\section{Highlights}

- Filial play therapy reduced the severity of hyperactivity and increased the attention of children with Attention Deficit Hyperactivity Disorder (ADHD).

- The Adlerian play therapy reduced the severity of hyperactivity and increased attentional performance of children with ADHD.

- Filial play therapy had a more constructive effect compared with the Adlerian play therapy on the attention and hyperactivity of the children.

\section{Plain Language Summary}

Children with ADHD have symptoms of hyperactivity, impulsivity, lack of attention, and disruption of social relationships. In addition to pharmacy therapy, it is shown that the non-prescriptive methods like play therapy could also be effective in treating them. In this study, the effect of two play therapy methods, including Filial (child-parents) and Adlerian (child-therapist) play therapy on increasing the attention and reduction of hyperactivity has been investigated and compared in these children. The result showed that both methods have been effective in increasing the attention and diminishing their hyperactivity. However, Filial therapy had a more beneficial effect compared with the Adlerian play therapy on the attention and hyperactivity of children.

\section{Introduction}

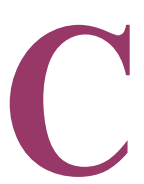

hildren with Attention Deficit Hyperactivity Disorder (ADHD) have a persistent and repetitive pattern of $\mathrm{ADHD}$ and impulsivity that is obstructive and delaying for the child's growth [1]. The prevalence of ADHD was estimated at about $0.5 \%$ in children and $2.5 \%$ in adults and this disorder is prevalent among males 3 times more than females [2]. Its prevalence in 7 to 12 -year-old Iranian children was reported from $3 \%$ to $6 \%$ [3]. The causes of this disorder were divided into two categories, including biological and psychological factors [4-10].

In children with ADHD, the abilities of awareness, time management, adaptability, physical activity, and communications are impaired. Also, the structures and functions of the body, mental functions, and sensory functions were disrupted, which can be modified with play therapy by an occupational therapist $[1,11]$.

The child fulfills his sensory-motor needs and depletes his energy by playing [12]. Play is a key area of occupational therapy activity in children, often defined as a childhood primary work and is a fundamental concept in occupational therapy $[13,14]$. According to the Canadian Occupational Therapists Association, the play for children is considered a basic requirement [13].
According to the study of Dighton, there are 3 main play therapy methods, including Child-centered, therapist-centered, and a combinative method (child-parents/ therapist relationship therapy) [15]. In this study, Filial Therapy (FT) and Adlerian Therapy (AT) were used as a child-parents relationship therapy and child-centered therapy methods, respectively. FT is a short-term intervention that incorporates a combination of play therapy and family therapy. The therapist trains the family and monitors their activities, and the parents receive childcentered treatment sessions with their children at home as a safe and acceptable environment for the children [16]. The AT approach is performed in the playing room between the child and the therapist with a warm relationship that leads to positive changes [17].

Studies indicated that the FT method had a significant effect on the reduction of the disorders of children with ADHD such as increased self-esteem, sharing skills, and improving behavioral problems after 10 sessions $[11,18]$. Also, a meta-analysis study showed that the AT method could have a moderately positive effect on resolving the disorders of children with ADHD [19].

For children with ADHD, many interventions have been used, such as psychosocial, pharmaceutical, and behavioral therapies. These interventions have been effective in decreasing the disorders of children with ADHD [11]. Although these methods were effective, non-prescriptive strategies like play therapy can be used, 
but the effects of different types of play therapies on the severity of these disorders have not been studied and are unclear $[12,19]$. Considering the effectiveness of play therapy, no similar study has yet investigated the two methods of play therapy on children with ADHD. So, the researchers aimed at assessing the impact of two treatment methods on the hyperactivity and attention of children with ADHD.

\section{Methods}

This single-blinded randomized clinical trial study was carried out on children with ADHD and their parents from February 20 to May 5, 2014, at the Faculty of Rehabilitation of Iran University of Medical Sciences, Play Therapy Clinic of the Department of Occupational Therapy, and Haft Sang Play Therapy Institute in Tehran. The study population included the children aged 6-15 years with ADHD diagnosed by psychiatrists.

To estimate the sample size, the following formula (Formula 1) was used. The type I error and power was considered 0.05 and 0.9 , respectively. Accordingly, 31 cases were estimated considering the possible attrition and 20 samples were taken more than the calculated amount; in total, 51 samples were randomly selected and allocated to 2 intervention groups and 1 control group by the blocked method. Each group included 17 subjects.

The Formula 1 of sample size:

$$
\begin{gathered}
n=\frac{2{\sigma^{2}}_{d}\left(z 1-\frac{a}{2}+z 1-\beta\right)^{2}}{\delta^{2}} \\
\sigma_{d}^{2}=\sigma_{1}^{2}+\sigma_{2}^{2}-2 p \sigma_{1} \sigma_{2}
\end{gathered}
$$

The inclusion criteria included suffering from ADHD diagnosed by a psychiatrist, being 6-15 years old, obtaining the required score on the CSI-4 scale, having no mental retardation and associated disorders (LD, oppositional defiant disorder, etc.), having no history of seizure and psychotropic substance-using according to the psychiatrist's diagnosis, having no obvious physical impairments in sensory or motor development, having no significant psychotic symptoms, diseases, or specific disorders (autism, Down syndrome, genetic disorders, etc.) in children, having parents with high school education, and having parents with no psychiatric disorders such as mood disorders, schizophrenia, etc. Children and parents, who did not want to participate in the study and failed to complete the treatment sessions (at least 6 sessions) were excluded.
The project was implemented in the following phases: Phase 1: The first step was to explain the project and collect the study population that was done in 3 ways: 1.Researcher referral to clinics and psychiatric clinics of the selected centers, 2. In-person and correspondence contact via e-mail and SMS system to counsel psychology centers, rehabilitation centers, and children's education centers with special needs, and 3. Giving the necessary explanations and invitation through social networks and presenting the study.

Phase 2: After completing the notification stage, 300 patients had inclusion criteria; then, in the completion of the definitive diagnosis of ADHD, the primary interview and the collection of background data revealed that 75 patients, according to the definitive diagnosis of children psychiatrists, had the combination type of ADHD and were eligible to enter the study; 24 of them discontinued because of non-acceptance of other conditions, such as filming play sessions or other reasons. Eventually, the total number of people invited to study was calculated through a formula of sample size and a possible drop of 51 people.

Phase 3: At this stage, the parents were presented and asked to complete the checklist of the research project evaluation forms previously provided by the research team in the following order: Read the text about the purpose of the project carefully; read the informed consent carefully, ask questions to resolve the ambiguity, and after convict with full consent, sign the form (this form contains all legal information); fill the demographic information; and complete the CSI-4 standard questionnaire.

Phase 4: Determine the appropriate time for Test of Everyday Attention for Children (TEA-Ch) by the blinded occupational therapist examiner (this test requires a special environment for the presence of the child and enough time to run).

Phase 5: At this stage, the groups were matched in terms of age, gender, and receiving treatment interventions such as medication, occupational therapy, and other services; then, the subjects were randomized between groups in the form of blocked blocks; 51 subjects in the study were divided into three groups (each group 17), namely 2 interventional groups (FT and AT) and a control group. It is worth noting that this study was single-blinded, in which the evaluators, parents, and therapists were unaware of the pre-test, posttest, and follow-up processes.

Phase 6: At this stage, interventions were implemented (summary of program description are explicated in the 


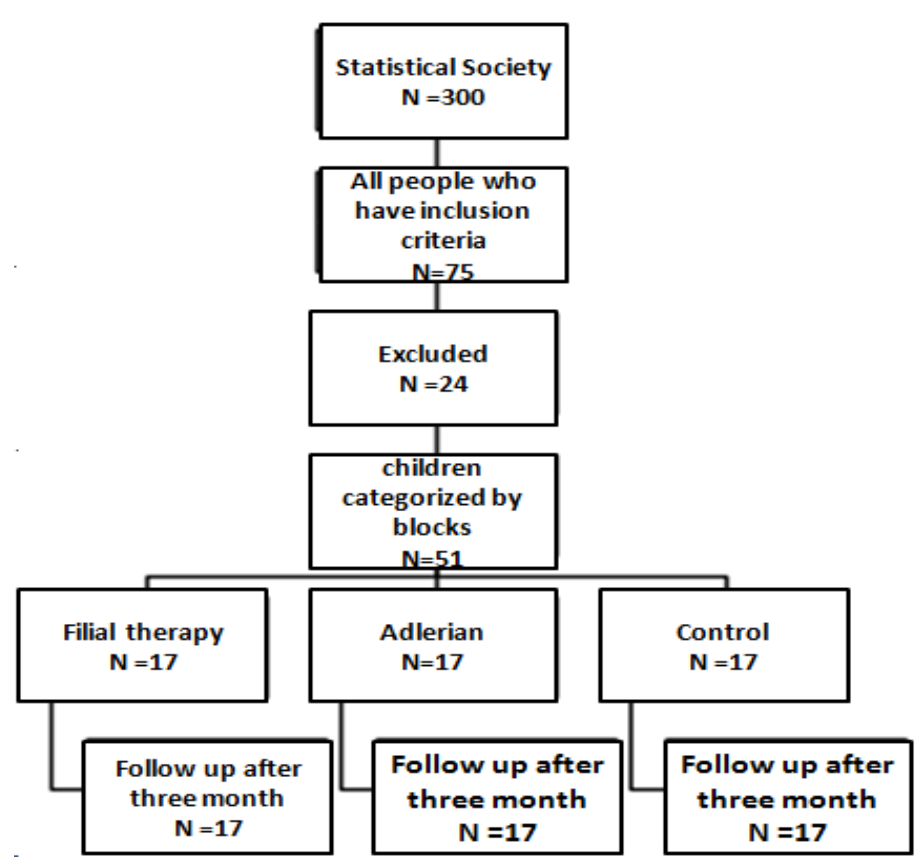

Figure 1. Process of the research

Iranian Rehabilitation \ournal

intervention section) for 10 weeks by unaware occupational therapists; then, the post-test was performed.

Phase 7: At this stage, 3 months after the post-test, the follow-up test was performed.

\section{Data collection}

The data were collected by a demographic form, Child Symptom Inventory-4 (CSI-4), and TEA-Ch. The CSI-4 is a behavioral scale designed in 1984 and revised in 1994 by Spearfakin and Gadu. The SCI-4 is a 4-point (0-4) scale with 2 forms for parents with 112 items and for teachers with 77 items. The teacher's form has 77 questions that cover 9 major sub-scales of behavioral disorders. In our study, the hyperactivity disorder was assessed by only group A (sub-scale) of teachers form. This questionnaire was standardized in Iran with the test -retest reliability of between 90\%-92\% and Cronbach alpha of 0.92 [20].

The TEA-Ch measures the ability of children in the areas of selective attention, maintaining attention, and the transfer of attention from subject to subject and the control of verbal and motor responses. This test was designed to evaluate children and adolescents in the age ranged from 6-16 years and has been standardized. The sensitivity of this test is confirmed for ADHD in children [21]. The content validity and reliability of this test were approved in Iranian normal children aged 8-11 years. The moderate to good test-retest reliability was indicated with the ICC from 0.40-0.82. Moreover, the inter-rater reliability was $0.78-1$ (excellent). Discriminate validity between the TEA-Ch and 4 subscales of the Wechsler's intelligence scale for the children-fourth edition was assessed; only 5 subtests of TEA-Ch were correlated with Wechsler's subscales ( $\mathrm{r}=-0.314-0.339)$ [22].

\section{Intervention}

The researcher first visited the selected centers and examined all those who were eligible to study; they were 300 subjects, of whom 75 subjects were eligible to enter the study. Of these, 24 subjects discontinued the study and 51 subjects were divided into 3 groups (17 subjects in each group). The two experimental groups and a control group (Figure 1).

Adlerian group: A playroom equipped with a variety of toys, including: A. family toys (such as dolls, puppets, animal families, bowls, plates, and puppet houses); B. Horrible toys (such as snakes, insects, and massive animal or anything else that seems horrible to children); $\mathrm{C}$. Aggressive toys (such as guns, game soldiers, bracelets, and boxing bags); D. Illustrated toys (such as drawing, pencil, marking, finger painting, or other artistic tools); and E. Fantasy toys (such as masks, medical instruments, dolls, phones, hats, and toy cars). Each session of the play therapy took 45 minutes and 3 sessions per week were held for 10 weeks in 4 stages (Table 1).

FT group: Firstly, play therapy with a focus on the childparent relationship was taught to parents. The therapist trained the parents in 10 sessions (Table 2) and each ses- 
Table 1. Each session schedule of play therapy in Adlerian group

Stages $\begin{aligned} & \text { Schedule } \\ & \text { Establishing an intimate-emotional relationship with the child, performing techniques such as behavior therapy, } \\ & \text { repetition of concepts, emotional reflection, encouragement, presentation, answering questions, and communication } \\ & \text { techniques such as cleaning the playroom during the first } 5 \text { sessions. }\end{aligned}$
$\begin{array}{r}\text { Establishing an intimate-emotional relationship with the child, examining the child's lifestyle, exploring and discovering } \\ \text { the lifestyle of the family, and assuming the methods of child's growth by the therapist during the second } 5 \text { sessions. }\end{array}$
Establishing an intimate-emotional relationship with the child, designing imagery, and storytelling during 10 sessions.
Establishing an intimate-emotional relationship with the child and practicing new behaviors with children by role-
playing during 10 sessions.

Irranian Rehabilitation Journa

sion lasted for 45 minutes to 1 hour. Four skills including structuring, empathic listening, child-centered imaginary play, and limit setting are essential in FT that was also trained to the parents. Then, the parents performed and continued the learned skills (play therapy) daily for over 30 minutes for 10 weeks with their children. Parents recorded their exercises on video and checked them each week by the research team. Each week, 1 or 2 parents brought their videotapes to be reviewed and discussed. The structure of the parent group consists of 6-8 parents and therapists, who sit in a circle and discuss.

\section{Data analysis}

The data were analyzed by SPSS V. 22 (SPSS Inc, Chicago, IL, USA). The normality of the data was assessed by the Shapiro-Wilk test. The result showed that the distribution of data was not normal. Therefore, nonpara- metric tests were used. The descriptive statistics were done by Mean $\pm \mathrm{SD}$, and frequency. Analytical statistics were done by the Chi-squared test, analysis of covariance, Man-Whitney, Kruskal-Wallis tests, as well as the generalized estimating equation. $\mathrm{P}<0.05$ were considered as statistically significant.

\section{Results}

Table 3 presents the Mean \pm SD age of the children and their parents. The girls and boys participated in the study.

Table 4 presents the Mean \pm SD of children's attention and hyperactivity score in the three groups. The result showed no significant difference in the mean score of attention and hyperactivity in the three groups $(\mathrm{P}>0.05)$. The difference in the mean score of them was statisti-

Table 2. Ten training sessions for parents in Filial Therapy

\section{Ten Training Sessions for Parents}

Educational goals and reflective responses

Basic principles for gaming sessions

Skills and methods of parent-child play

The structure of monitoring and determining the limits

Review session of play skills

Supervising and giving the right to choose

How to build self-esteem

Supervision and encouragement against the acclaim

Generalize skills

Evaluation and conclusion 
cally significant in the three groups after the intervention $(\mathrm{P}<0.05)$; it means that after the intervention, the rate of attention was increased and the rate of hyperactivity was decreased in the intervention groups. Also, the difference mean score of attention and hyperactivity among groups at the follow-up was statistically significant $(\mathrm{P}<0.05)$.

The result showed that the intervention was effective and stable in increasing attention and reducing the hyperactivity score of children. For further investigation, the difference mean score of attention and hyperactivity among groups was compared mutually in each stage (Tables 5 and 6).

As presented in Table 5 for attention, in the Filial group, the difference mean scores in the pre-test, post-test, and follow-up were significantly different $(\mathrm{P}<0.001)$. In the Adlerian group, the difference mean scores in the pre-test, post-test, and follow-up were significantly different $(\mathrm{P}<0.001)$. In the control group, the difference mean scores of attention in the pre-test, post-test, and follow-up were not significant $(\mathrm{P}>0.05)$. As presented in Table 5, for hyperactivity, in the Filial group, the difference mean scores in the pre-test and follow-up stages were significantly different $(\mathrm{P}=0.043)$. In the Adlerian group, the difference mean scores in the pre-test with the post-test $(\mathrm{P}=0.001)$ and follow-up $(\mathrm{P}=0.001)$ were significantly different. In the control group, the difference mean scores in the post-test and follow-up stages was significant $(\mathrm{P}=0.024)$.

Table 3. Mean $\pm \mathrm{SD}$ age of the parent and children

\begin{tabular}{cc}
\hline Age & Mean \pm SD \\
\hline Child & $8.08 \pm 2.00$ \\
Mother & $37.55 \pm 5.83$ \\
Father & $42.18 \pm 7.22$ \\
\hline
\end{tabular}

Ilranian Rehabilitation Journa

Table 4. Mean \pm SD of attention and hyperactivity score before and after the intervention

\begin{tabular}{|c|c|c|c|c|c|c|c|c|}
\hline \multirow{3}{*}{$\begin{array}{l}\text { Groups/ } \\
\text { Time }\end{array}$} & \multicolumn{6}{|c|}{ Mean $\pm S D$} & \multicolumn{2}{|c|}{$\mathbf{P}^{*}$} \\
\hline & \multicolumn{2}{|c|}{ Filial } & \multicolumn{2}{|c|}{ Adlerian } & \multicolumn{2}{|c|}{ Control } & \multirow{2}{*}{ Attention } & \multirow{2}{*}{$\begin{array}{c}\text { Hyperac- } \\
\text { tivity }\end{array}$} \\
\hline & Attention & Hyperactivity & Attention & Hyperactivity & Attention & Hyperactivity & & \\
\hline Pre-test & $8.47 \pm 5.32$ & $23.94 \pm 13.44$ & $6.71 \pm 5.31$ & $17.69 \pm 3.70$ & $9.71 \pm 5.35$ & $24.25 \pm 10.31$ & 0.285 & 0.163 \\
\hline Post-test & $15.59 \pm 2.78$ & $20.82 \pm 11.62$ & $12.24 \pm 3.32$ & $15.19 \pm 3.33$ & $10.41 \pm 3.24$ & $25.38 \pm 11.47$ & 0.000 & 0.16 \\
\hline Follow-Up & $15.80 \pm 2.50$ & $20.76 \pm 11.13$ & $12.90 \pm 3.12$ & $15 \pm 3.50$ & $9.92 \pm 4.89$ & $24.81 \pm 11.96$ & 0.000 & 0.28 \\
\hline
\end{tabular}

*Kruskal-Wallis test

Iranian Rehabilitation \ournal 
Table 5. The difference mean scores of attention and hyperactivity in two groups between the times of the tests

\begin{tabular}{cccccc}
\hline \multirow{2}{*}{ Groups } & Time of Tests & \multicolumn{2}{c}{ Difference Between Mean Scores } & \multicolumn{2}{c}{ P* } \\
\cline { 3 - 6 } & & Attention & Hyperactivity & Attention & Hyperactivity \\
\hline \multirow{3}{*}{ Filial group } & Pre-test/ Post-test & -6.56 & 3.12 & 0.045 & 0.054 \\
& Pre-test/ Follow-up & -6.80 & 3.18 & 0.001 & 0.043 \\
& Post-test/ Follow-up & -0.23 & 0.06 & 0.947 & 0.853 \\
\cline { 2 - 6 } Adlerian group & Pre-test/ Post-test & -5.94 & 2.50 & 0.037 & 0.001 \\
& Pre-test/ Follow-up & -10.42 & 2.69 & 0.000 & 0.001 \\
& Post-test/ Follow-up & -4.48 & 0.19 & 0.163 & 0.353 \\
& Pre-test/ Post-test & -6.07 & -1.13 & 0.028 & 0.311 \\
Control group & Pre-test/ Follow-up & -10.05 & -0.56 & 0.000 & 0.627 \\
& Post-test/ Follow-up & -3.97 & 0.56 & 0.212 & 0.024 \\
\hline
\end{tabular}

*Mann-Whitney U test

Iranian Rehabilitation Journa

plained in the following way: in FT, parents are trained to provide an easy and productive environment for growth, in which the child could reach their potential capacity. In FT, an opportunity is given to hyperactive children and their parents to understand the better condition of each other and during interaction and communication with each other, they gain more cognition and enjoyment and improve their relationship [25].

In relation to the attention, in the intervention group of receiving $\mathrm{FT}$, the difference in mean attention scores in the pre-test and post-test was significant; it can be concluded that the FL method has increased the attention of the children. The findings are in line with the results of other studies on the effect of FL in improving symptoms or reducing disorders in children aged 6 to 15 years (all studies of FT reported 1977-2011). Also, the result of a meta-analysis study indicated that FT compared with other play therapies has a more therapeutic effect on children with ADHD [23]. The overall results of these stud- ies confirm and emphasize the impact of such a treatment method on improving the performance of children in this age range.

In the current study, the AT method decreased the hyperactivity of children with ADHD both at the post-test and follow-up stages compared with the pre-test. The study of Landreth confirmed that the child therapist's approach is effective in decreasing the behavioral symptoms of children with ADHD and has a significant effect on reducing the complaints of these children's behaviors, which is consistent with the results of this study [17]. This result is in line with the related studies of Schell, showing that the therapeutic effects of the child therapist's approach in reducing behavioral symptoms of children aged 6 to 12 years are remarkable [12].

Finally, the results of the current study showed that FT compared with the AT method had high efficacy in reducing the symptoms of hyperactivity. It might be justified by the presence of specialists in all sessions,

Table 6. Difference mean scores of attention and hyperactivity between the groups in each test time

\begin{tabular}{|c|c|c|c|c|c|}
\hline \multirow{2}{*}{ Time of Tests } & \multirow{2}{*}{ Groups } & \multicolumn{2}{|c|}{ Difference Between Mean Scores } & \multicolumn{2}{|c|}{$\mathbf{P}^{*}$} \\
\hline & & Attention & Hyperactivity & Attention & Hyperactivity \\
\hline \multirow{3}{*}{ Pre-test } & Adlerian-Filial & -1.47 & -6.56 & 0.442 & 0.045 \\
\hline & Adlerian-Control & -3.00 & -6.80 & 0.145 & 0.001 \\
\hline & Filial-Control & -1.24 & -0.23 & 0.450 & 0.947 \\
\hline \multirow{3}{*}{ Post Test } & Adlerian-Filial & -3.35 & -5.94 & $<0.001$ & 0.037 \\
\hline & Adlerian-Control & 1.83 & -10.42 & 0.051 & 0.000 \\
\hline & Filial-Control & 5.18 & -4.48 & $<0.001$ & 0.163 \\
\hline \multirow{3}{*}{ Follow-up } & Adlerian-Filial & -2.90 & -6.07 & $<0.001$ & 0.028 \\
\hline & Adlerian-Control & 2.98 & -10.05 & 0.512 & 0.000 \\
\hline & Filial-Control & 5.88 & -3.97 & $<0.001$ & 0.212 \\
\hline
\end{tabular}

*Mann-Whitney U test 
cooperation of specialists and parents in the clinics and more planning-counseling, and parenting education. In this area, the bombardment of attention by parents and non-disturbance by other residents at home increased the sense of satisfaction in interactions, the allocation of a special time, and special conditions in the therapeutic sessions of FT at home, which led to an increased level of attention in children.

\section{Conclusion}

Both interventions of play therapy had reduced the intensity of hyperactivity and increased children's attention. But, the effect of a method that focuses on family education and family practice has been greater and suggests that the use and planning for parental involvement in the treatment and rehabilitation of the child speed up the recovery process, and the level of positive family and the child performance go up. Also, children in the growth process in the current society, which is rapidly equipped with facilities and technology, have replaced most of the individual functions and have problems with the physical, sensory, psychological, and emotional development that is proposed in this regard; the planning and public education is provided through mass media programs for parents to improve interactions with children.

A large number of questionnaires, the timeliness of filling them out, and the limited time of holding sessions were among the limitations of this study. Moreover, for future studies, it is suggested to survey the effectiveness of FT with different sessions in ADHD children or with other diagnoses; it is also suggested to compare the different types of play therapy with a specific model in occupational therapy such as cognitive-behavioral therapy.

\section{Compliance with ethical guidelines}

The required approval for conducting this study on human subjects was received from Iran University of Medical Sciences under the number 92-د-1679-130. The purposes of the study were explained to the participants, and they were informed of a voluntary participate in or withdraw from the study without experiencing any alteration in their care schemes. All participants signed the written informed consent for contribution. The confidentiality of information obtained from participants and the preservation of the names of subjects were considered, using coding. Accept permission was obtained from the legal supervisor of the children to filming treatment sessions.

\section{Ethical Considerations}

\section{Compliance with ethical guidelines}

All ethical principles were considered in this article.

\section{Funding}

This research did not receive any specific grant from funding agencies in the public, commercial, or not-forprofit sectors.

\section{Authors' contributions}

Designing and performing tests, collecting the data, and co-writing the paper: Hooshang Mirzaie, Afsoon Hassani Mehraban, Fatemeh Ghasemifard, and Mehdi Jafari Oori; Performing the analysis: Hooshang Mirzaie and Afsoon Hassani Mehraban; Supervising the research: Hooshang Mirzaie, Afsoon Hassani Mehraban, and Seyed Ali Hosseini.

\section{Conflict of interest}

The authors declared no conflicts of interest.

\section{References}

[1] Bowyer P, Cahill SM. Pediatric Occupational Therapy Handbook-E-Book: A Guide to Diagnoses and Evidence-Based Interventions. Edinburgh: Elsevier Health Sciences; 2008.

[2] Leslie LK, Weckerly J, Plemmons D, Landsverk J, Eastman S. Implementing the American Academy of Pediatrics attention-deficit/hyperactivity disorder diagnostic guidelines in primary care settings. Pediatrics. 2004; 114(1):129-40. [DOI:10.1542/peds.114.1.129] [PMID] [PMCID]

[3] Khushabi K, Pour-Etemad H, Mohammadi M, Mohammadkhani P. The prevalence of ADHD in primary school students in Tehran. Medical Journal of The Islamic Republic of Iran (MJIRI). 2006; 20(3):147-50

[4] Faraone SV, Perlis RH, Doyle AE, Smoller JW, Goralnick JJ, Holmgren MA, et al. Molecular genetics of attentiondeficit/hyperactivity disorder. Biological Psychiatry. 2005; 57(11):1313-23. [DOI:10.1016/j.biopsych.2004.11.024] [PMID]

[5] Castellanos FX, Lee PP, Sharp W, Jeffries NO, Greenstein DK, Clasen LS, et al. Developmental trajectories of brain volume abnormalities in children and adolescents with attentiondeficit/hyperactivity disorder. JAMA. 2002; 288(14):1740-8 [DOI:10.1001/jama.288.14.1740] [PMID]

[6] Linnet KM, Dalsgaard S, Obel C, Wisborg K, Henriksen TB, Rodriguez A, et al. Maternal lifestyle factors in pregnancy risk of attention deficit hyperactivity disorder and associated behaviors: Review of the current evidence. American Jour- 
nal of Psychiatry. 2003; 160(6):1028-40. [DOI:10.1176/appi. ajp.160.6.1028] [PMID]

[7] Thapar A, Fowler T, Rice F, Scourfield J, van den Bree M, Thomas $\mathrm{H}$, et al. Maternal smoking during pregnancy and attention deficit hyperactivity disorder symptoms in offspring. American Journal of Psychiatry. 2003; 160(11):1985-9. [DOI:10.1176/appi.ajp.160.11.1985] [PMID]

[8] Braun JM, Kahn RS, Froehlich T, Auinger P, Lanphear BP. Exposures to environmental toxicants and attention deficit hyperactivity disorder in US children. Environmental Health Perspectives. 2006; 114(12):1904-10. [DOI:10.1289/ehp.9478] [PMID] [PMCID]

[9] Swanson JM, Kinsbourne M, Nigg J, Lanphear B, Stefanatos GA, Volkow N, et al. Etiologic subtypes of attention-deficit/ hyperactivity disorder: Brain imaging, molecular genetic and environmental factors and the dopamine hypothesis. Neuropsychology Review. 2007; 17(1):39-59. [DOI:10.1007/ s11065-007-9019-9] [PMID]

[10] Chronis AM, Chacko A, Fabiano GA, Wymbs BT, Pelham WE. Enhancements to the behavioral parent training paradigm for families of children with ADHD: Review and future directions. Clinical Child and Family Psychology Review. 2004; 7(1):1-27. [DOI:10.1023/B:CCFP.0000020190.60808.a4] [PMID]

[11] Baggerly JN, Ray DC, Bratton SC. Child-centered play therapy research: The evidence base for effective practice. Hoboken: John Wiley \& Sons; 2010. [DOI:10.1002/9781118269626]

[12] Schell BA, Gillen G, Scaffa M, Cohn ES. Willard and Spackman's occupational therapy. Philadelphia: Lippincott Williams \& Wilkins; 2013.

[13] Case-Smith J, Allen AS, Pratt PN. Occupational therapy for children. St. Louis: Mosby; 2010.

[14] Parham LD, Fazio LS. Play in occupational therapy for children. St. Louis: Mosby; 2008. [DOI:10.1016/B978-0323029544.10001-7]

[15] Dighton R. Towards a definition of play therapy. Play Therapy. 2001; 2001 (28):910.

[16] Ray D, Bratton S, Rhine T, Jones L. The effectiveness of play therapy: Responding to the critics. International Journal of Play Therapy. 2001; 10(1):85-108. [DOI:10.1037/h0089444]

[17] Landreth GL, Bratton SC, Kellam T, Blackard S. Child Parent Relationship Therapy (CPRT) Treatment Manual: A 10-Session Filial Therapy Model for Training Parents. New York: Routledge; 2006. [DOI:10.4324/9780203956342]

[18] Athanasiou MS, Gunning MP. Filial therapy: Effects on two children's behavior and mothers' stress. Psychological Reports. 1999; 84(2):587-90. [DOI:10.2466/pr0.1999.84.2.587] [PMID]

[19] Lin YW, Bratton SC. A meta-analytic review of childcentered play therapy approaches. Journal of Counseling \& Development. 2015; 93(1):45-58. [DOI:10.1002/j.15566676.2015.00180.x]

[20] Schaefer CE, Kaduson HG . ]Play therapy (E Mohammad esmaeil, Persian )]. 3rd ed. Tehran: Danjeh; 2007.

[21] Chan RC, Wang L, Ye J, Leung WW, Mok MY. A psychometric study of the Test of Everyday Attention for Children in the Chinese setting. Archives of Clinical Neuropsychology. 2008; 23(4):455-66. [DOI:10.1016/j.acn.2008.03.007] [PMID]

[22] Fathi N, Hassani Mehraban A, Akbarfahimi M, Mirzaie H. Validity and Reliability of the Test of Everyday Attention for Children (TEA-Ch) in Iranian 8-11 Year Old Normal Students. Iranian Journal of Psychiatry and Behavioral Sciences. 2017; 11(1):e2854. [DOI:10.5812/ijpbs.2854]

[23] Bratton SC, Ray D, Rhine T, Jones L. The efficacy of play therapy with children: A meta-analytic review of treatment outcomes. Professional Psychology: Research and Practice. 2005; 36(4):376-90. [DOI:10.1037/0735-7028.36.4.376]

[24] Van der Oord S, Prins P, Oosterlaan J, Emmelkamp P. Efficacy of methylphenidate, psychosocial treatments and their combination in school-aged children with ADHD: A metaanalysis. Clinical Psychology Review. 2008; 28(5):783-800. [DOI:10.1016/j.cpr.2007.10.007] [PMID]

[25] Tanta KJ, Deitz JC, White O, Billingsley F. The effects of peer-play level on initiations and responses of preschool children with delayed play skills. American Journal of Occupational Therapy. 2005; 59(4):437-45. [DOI:10.5014/ajot.59.4.437] [PMID] 
This Page Intentionally Left Blank 